Check for updates

Cite this: RSC Adv., 2019, 9, 3479

Received 15th November 2018

Accepted 4th January 2019

DOI: $10.1039 / c 8 \mathrm{ra09348b}$

rsc.li/rsc-advances

\section{Hydrothermal synthesis of $\mathrm{MoS}_{2}$ nanosheet loaded $\mathrm{TiO}_{2}$ nanoarrays for enhanced visible light photocatalytic applications}

Miao Zhang, (DD acd Shun Wang, ${ }^{\text {b } Z i l i a n g ~ L i, ~}{ }^{a}$ Chunwang Liu, ${ }^{a}$ Rui Miao, ${ }^{\text {b } G a n g ~ H e, ~(D) ~ a c ~}$ Min Zhao, ${ }^{\text {bc }}$ Jun Xue, ${ }^{b}$ Zhiyuan Xia, ${ }^{b}$ Yongqi Wang, ${ }^{b}$ Zhaoqi Sun ${ }^{a}$ and Jianguo Lv ${ }^{\star b c}$

A molybdenum disulfide $\left(\mathrm{MoS}_{2}\right)$ nanosheet-decorated titanium dioxide $\left(\mathrm{TiO}_{2}\right)$ NRA heterojunction composite was fabricated successfully through a two-step hydrothermal approach. Microstructures and optical properties of specimens were characterized by field-emission scanning electron microscopy, $X$-ray diffractometry, X-ray photoelectron spectroscopy, and ultraviolet-visible spectroscopy. The gaps of the $\mathrm{TiO}_{2}$ nanorods have been filled with tiny $\mathrm{MoS}_{2}$ nanosheets, which can increase the surface area of $\mathrm{MoS}_{2} /$ $\mathrm{TiO}_{2}$ NRA composite thin films. In addition, the photocatalytic activity of the thin films were measured and discussed in greater detail. The appropriate hydrothermal reaction temperature of $\mathrm{MoS}_{2}$ is important for the growth of perfect $\mathrm{MoS}_{2} / \mathrm{TiO}_{2}$ NRA composites with significantly enhanced photocatalytic performance. The photodegradation rate and $k$ value of $\mathrm{MoS}_{2}-220 / \mathrm{TiO}_{2}$ are $86 \%$ and $0.0105 \mathrm{~min}^{-1}$, respectively, which are much larger than those of blank $\mathrm{TiO}_{2}$. The enhanced photocatalytic performance could be attributed to the higher visible light absorption and the reduced recombination rate of photogenerated electron-hole pairs.

\section{Introduction}

In recent years, a large and growing literature has investigated the photocatalytic degradation and solar energy conversion to provide clean fuels ${ }^{1-3}$ for addressing the energy crisis and environmental pollution. Titanium dioxide $\left(\mathrm{TiO}_{2}\right)$ as a semiconductor photocatalytic material has been broadly investigated due to its high photocatalytic activity, chemical stability, low cost and nontoxicity. ${ }^{4}$ In order to improve the photocatalytic activities, many efforts have been made for the fabrication of various morphologies of $\mathrm{TiO}_{2}$, such as hollow spheres, hierarchical microspheres, nanorods, nanotubes and porous networks. $^{5-7}$ However, the fast recombination of photogenerated electron-hole pairs and large band gap $(3.2 \mathrm{eV})$ of $\mathrm{TiO}_{2}$ limit the use of sunlight as well as photocatalytic activity. In order to overcome these drawbacks, rational designs of $\mathrm{TiO}_{2}$ based heterojunction photocatalysts with desirable architectural structure/morphology have been put into effect..$^{8-11}$ It is well-known that two-dimensional $\mathrm{MoS}_{2}$ is a potential candidate for enhancing the visible light absorption and charge separation ability. Recently, $\mathrm{MoS}_{2} / \mathrm{TiO}_{2}$ heterostructures with diverse

\footnotetext{
${ }^{a}$ School of Physics and Materials Science, Anhui University, Hefei 230039, China ${ }^{b}$ School of Physics and Materials Engineering, Hefei Normal University, Hefei 230601, China. E-mail: lvjg1@163.com; Fax: +86 551 63674131; Tel: +86 55163674132 ${ }^{c}$ Co-operative Innovation Research Center for Weak Signal-Detecting Materials and Devices Integration, Anhui University, Hefei 230601, PR China

${ }^{d}$ Key Laboratory of Materials Physics, Institute of Solid State Physics, Chinese Academy of Sciences, Hefei, 230031, PR China
}

morphologies have been reported by researchers and have shown high photocatalytic activities in the visible light region. ${ }^{12-14}$ However, most of the $\mathrm{MoS}_{2} / \mathrm{TiO}_{2}$ heterostructures were powder materials, which were either difficult to recycle or would require additives in order to prepare the electrodes. In order to overcome these drawbacks, researchers made great efforts to prepare the film-based heterostructure composites with enhanced photocatalytic performances. Zheng et al. ${ }^{15}$ prepared the hierarchical $\mathrm{MoS}_{2}$ nanosheet@TiO 2 nanotube arrays via anodization and hydrothermal methods. Photocatalytic activity of the compositing $\mathrm{MoS}_{2} @ \mathrm{TiO}_{2}$ hybrids can be enhanced by means of appropriate modification of $\mathrm{MoS}_{2}$ on $\mathrm{TiO}_{2}$ nanotube arrays. To the best of our knowledge, the studies on the synthesis of $\mathrm{MoS}_{2}$ nanosheet coating on the $\mathrm{TiO}_{2}$ nanoarrays are limited.

Herein, we demonstrate a facile two-step hydrothermal method to prepare $\mathrm{MoS}_{2} / \mathrm{TiO}_{2}$ NRA composite thin films with a highly-ordered three-dimensional hierarchical structure. The unique hierarchical structure of $\mathrm{MoS}_{2} / \mathrm{TiO}_{2}$ NRA heterojunctions was propitious to improve the light harvesting and charge separation rates. The novel $\mathrm{MoS}_{2} / \mathrm{TiO}_{2}$ NRAs exhibit enhanced photocatalytic activity due to the lower recombination rate and higher visible light absorption compared with the pure $\mathrm{TiO}_{2}$ NRAs.

\section{Experimental}

A simple two-step hydrothermal approach was adopted to prepare $\mathrm{MoS}_{2}$ nanosheet-loaded highly ordered $\mathrm{TiO}_{2}$ 
nanoarrays (NRAs). $\mathrm{TiO}_{2}$ NRAs were synthesized via the hydrothermal method. Then, $0.68 \mathrm{~mL}$ of tetrabutyl titanate was mixed with $20 \mathrm{~mL}$ of hydrochloric acid and $20 \mathrm{~mL}$ of deionized water (DI water). The mixed solution was magnetically stirred for $30 \mathrm{~min}$ and transferred into a $50 \mathrm{~mL}$ Teflon-lined stainless steel autoclave. Subsequently, a clean FTO glass was placed vertically in the autoclave, which was heated at $150{ }^{\circ} \mathrm{C}$ for 10 hours and then cooled to room temperature. The obtained $\mathrm{TiO}_{2}$ NRAs were washed thoroughly with DI water and dried at $60{ }^{\circ} \mathrm{C}$ for several hours.

The preparation procedure of the $\mathrm{MoS}_{2} / \mathrm{TiO}_{2}$ NRA composite thin film is depicted as follows. $0.12 \mathrm{~g}$ thioacetamide $\left(\mathrm{C}_{2} \mathrm{H}_{5} \mathrm{NS}\right)$ and $0.06 \mathrm{~g}$ sodium molybdate $\left(\mathrm{Na}_{2} \mathrm{MoO}_{4} \cdot 2 \mathrm{H}_{2} \mathrm{O}\right)$ were dissolved in $40 \mathrm{~mL}$ DI water and magnetically stirred for $30 \mathrm{~min}$ to form a transparent solution. The mixed solution was transferred into a $50 \mathrm{~mL}$-Teflon-lined stainless steel autoclave. The $\mathrm{TiO}_{2} \mathrm{NRAs}$ were placed vertically in the autoclave, which was heated at $200{ }^{\circ} \mathrm{C}$ and $220^{\circ} \mathrm{C}$ for $24 \mathrm{~h}$. The $\mathrm{MoS}_{2} / \mathrm{TiO}_{2}$ NRA composite thin film was obtained after washing the product with DI water and drying at $60{ }^{\circ} \mathrm{C}$ for $12 \mathrm{~h}$.

Field-emission scanning electron microscopy (FE-SEM, S4800) was adopted to observe the topologies of the samples. An X-ray diffractometer (XRD) was used to record the diffraction patterns of the samples. Chemical compositions of the samples were analyzed via X-ray photoelectron spectroscopy (XPS, ESCALAB 250). The structural properties of the samples were examined using a laser micro-Raman spectrometer (Renishaw in Via-Reflex) at an excitation wavelength of $532 \mathrm{~nm}$. Optical properties of the samples were characterized by an ultravioletvisible spectrophotometer (UV-2550, Shimadzu). The photocatalytic performances of the samples were estimated by the degradation of methylene blue (MB) solution. A thin film $(25 \times$ $25 \mathrm{~mm}$ ) was placed in a glass culture dish containing $10 \mathrm{~mL} \mathrm{MB}$ solution (5 ppm), which was chosen as the simulated contaminant. Then, the glass culture dish was placed under the visiblelight irradiation from a Xenon lamp with a $420 \mathrm{~nm}$ cut-off filter. The photocatalytic performance can be estimated by comparing the absorbance of $\mathrm{MB}$ at a certain light irradiation with that of the initial MB solution at a characteristic wavelength of $664 \mathrm{~nm}$.

\section{Results and discussion}

Fig. 1 presents the top-view FE-SEM images of $\mathrm{TiO}_{2} \mathrm{NRAs}, \mathrm{MoS}_{2}$ 200/TiO 2 and $\mathrm{MoS}_{2}-220 / \mathrm{TiO}_{2}$ on an FTO substrate. As shown in the FE-SEM image in Fig. 1a, the $\mathrm{TiO}_{2}$ NRAs are well-aligned perpendicular to the FTO substrate. The nanorods have an average diameter of $\sim 100 \mathrm{~nm}$. In $\mathrm{MoS}_{2}-200 / \mathrm{TiO}_{2}$ (Fig. 1b), many tiny $\mathrm{MoS}_{2}$ nanosheets exist on the side and top facets of $\mathrm{TiO}_{2}$ nanorods. As the growth temperature of $\mathrm{MoS}_{2}$ increases to $220{ }^{\circ} \mathrm{C}$, the gap of the $\mathrm{TiO}_{2}$ nanorods fills with tiny $\mathrm{MoS}_{2}$ nanosheets, which form the well-stacked layered structure of $\mathrm{MoS}_{2}$.

Fig. 2 presents the XRD patterns of $\mathrm{TiO}_{2}$ NRAs, $\mathrm{MoS}_{2}-200 /$ $\mathrm{TiO}_{2}$ and $\mathrm{MoS}_{2}-220 / \mathrm{TiO}_{2}$. The diffraction peaks for the $\mathrm{TiO}_{2}$ NRAs match the standard peaks of rutile $\mathrm{TiO}_{2}$ phase (JCPDS card no. 65-0191) with the lattice parameters of $a=b=$ $0.4593 \mathrm{~nm}$ and $c=0.2958 \mathrm{~nm}$. Five characteristic peaks at $2 \theta=$
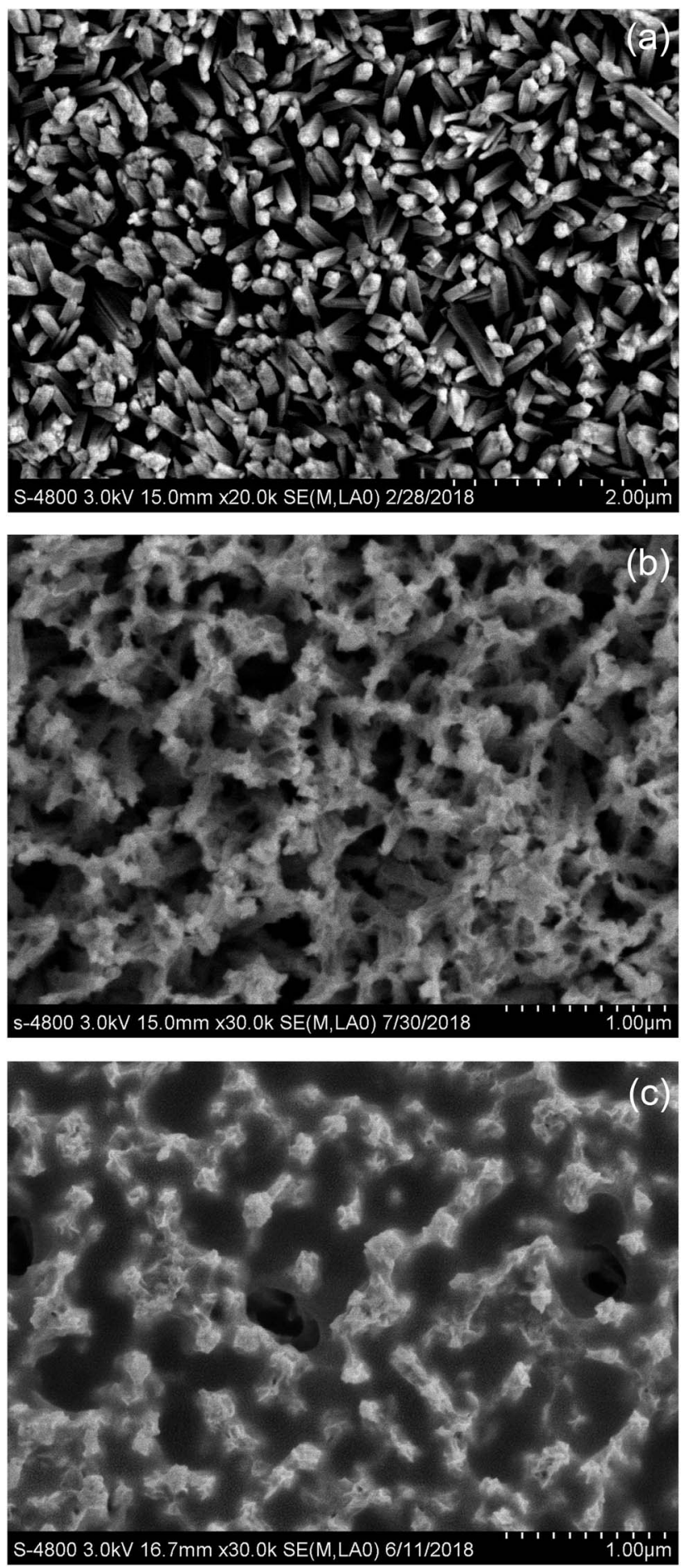

Fig. 1 Top-view FE-SEM images of (a) $\mathrm{TiO}_{2}$ NRAs, (b) $\mathrm{MoS}_{2}-200 / \mathrm{TiO}_{2}$, and (c) $\mathrm{MoS}_{2}-220 / \mathrm{TiO}_{2}$.

$36.08^{\circ}, 54.33^{\circ}, 62.77^{\circ}, 69.01^{\circ}$ and $69.82^{\circ}$ can be respectively assigned to the (101), (211), (002), (301) and (112) crystal facets of rutile $\mathrm{TiO}_{2}$. With regard to $\mathrm{MoS}_{2} / \mathrm{TiO}_{2}$ NRA composite thin films, all diffraction peaks of the rutile $\mathrm{TiO}_{2}$ phase still exist in the XRD patterns. These results indicate that the $\mathrm{TiO}_{2} \mathrm{NRAs}$ are well maintained in the hydrothermal process. Furthermore, the intensity of the diffraction peaks for rutile $\mathrm{TiO}_{2}$ of $\mathrm{MoS}_{2}-200$ / 


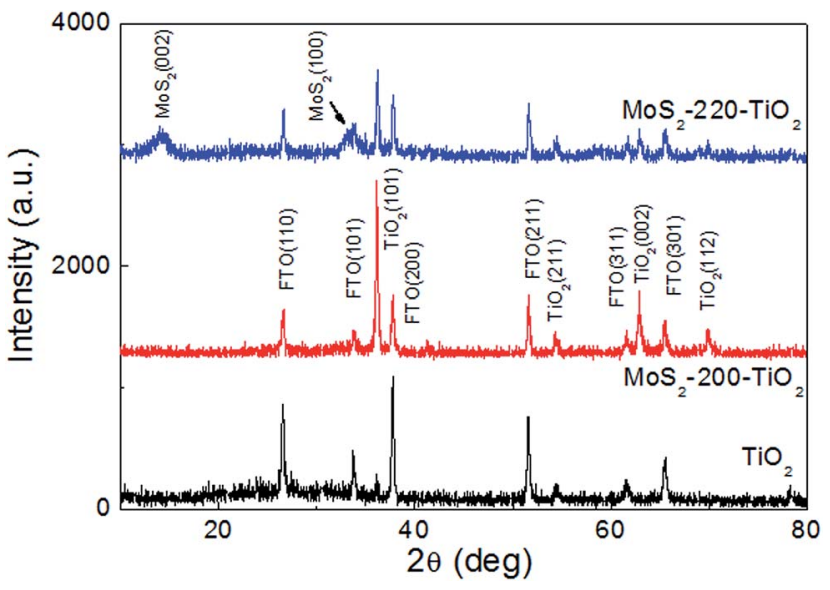

Fig. 2 XRD patterns of $\mathrm{TiO}_{2}$ NRAs, $\mathrm{MoS}_{2}-200 / \mathrm{TiO}_{2}$ and $\mathrm{MoS}_{2}-220 /$ $\mathrm{TiO}_{2}$.

$\mathrm{TiO}_{2}$ is stronger than that of rutile $\mathrm{TiO}_{2}$, which may be attributed to the recrystallization of rutile $\mathrm{TiO}_{2}$ in the second step of the hydrothermal process. The decrease in the diffraction peak intensities for $\mathrm{TiO}_{2}$ of $\mathrm{MoS}_{2}-220 / \mathrm{TiO}_{2}$ may be due to the shielding effect of the large amounts of $\mathrm{MoS}_{2}$ loaded onto $\mathrm{TiO}_{2}$. No diffraction peak for $\mathrm{MoS}_{2}$ has been observed in $\mathrm{MoS}_{2}-200$ / $\mathrm{TiO}_{2}$. Absence of the diffraction peak indicates that the modificatory $\mathrm{MoS}_{2}$ nanosheets on the $\mathrm{TiO}_{2}$ NRAs may only contain a spot of $\mathrm{MoS}_{2}$ nanosheets, which cannot be detected by XRD. Three characteristic peaks at $2 \theta=14.40^{\circ}, 33.52^{\circ}$ and $58.35^{\circ}$ have been observed in $\mathrm{MoS}_{2}-220 / \mathrm{TiO}_{2}$, which can be indexed to (002), (101) and (110) crystal facets of $\mathrm{MoS}_{2}$ (JCPDS card no. 657025), respectively. The stronger (002) diffraction peak that appeared in the XRD pattern of the sample indicates the formation of a well-stacked layered structure of $\mathrm{MoS}_{2} \cdot{ }^{16}$

In order to obtain the detailed topography of the binary composite thin film, TEM images of the $\mathrm{MoS}_{2}-220 / \mathrm{TiO}_{2}$ composites have been recorded. Fig. $3 \mathrm{a}$ and $\mathrm{b}$ represent the typical transmission electron microscopy (TEM) images of the $\mathrm{MoS}_{2}-220 / \mathrm{TiO}_{2}$ composite. It can be seen that the tiny $\mathrm{MoS}_{2}$ nanosheets cover the surface of $\mathrm{TiO}_{2}$ nanorods. Fig. 3c shows the high-resolution transmission electron microscopy (HRTEM) image of the composite thin film. The lattice fringes that are perpendicular to the growth direction have a lattice spacing of $0.32 \mathrm{~nm}$, which is equal to the lattice parameter in the (110) facet of the rutile $\mathrm{TiO}_{2}$. The lattice spacing is $0.62 \mathrm{~nm}$, which corresponds to the (002) plane of $\mathrm{MoS}_{2}$.

As shown in Fig. 4, the survey XPS spectra show that the dominant elements in $\mathrm{MoS}_{2}-220 / \mathrm{TiO}_{2}$ are Ti, O, S, Mo, and C (Fig. 4a). The high-resolution XPS spectra of Mo and S for $\mathrm{MoS}_{2}$ $220 / \mathrm{TiO}_{2}$ are shown in Fig. $4 \mathrm{~b}$ and c. The binding energies at 232.2 and $229.0 \mathrm{eV}$ with a separation energy close to $3.2 \mathrm{eV}$ are ascribed to the $\operatorname{Mo}_{3 / 2}$ and Mo3d $d_{5 / 2}$ of the Mo element in the tetravalent state. ${ }^{17}$ In addition, the binding energy at $235.9 \mathrm{eV}$ is ascribed to the $\operatorname{Mo}\left(3 \mathrm{~d}_{3 / 2}\right)$ signal of the Mo element in the hexavalent state, which results from the partial surface oxidation of $\mathrm{MoS}_{2}$ in air. ${ }^{16}$ As shown in Fig. 4c, the S2p spectrum can be deconvoluted into two peaks. The binding energies at 163.3 and $161.9 \mathrm{eV}$ are attributed to the $\mathrm{S}\left(2 \mathrm{p}_{1 / 2}\right)$ and $\mathrm{S}\left(2 \mathrm{p}_{3 / 2}\right)$ signals,
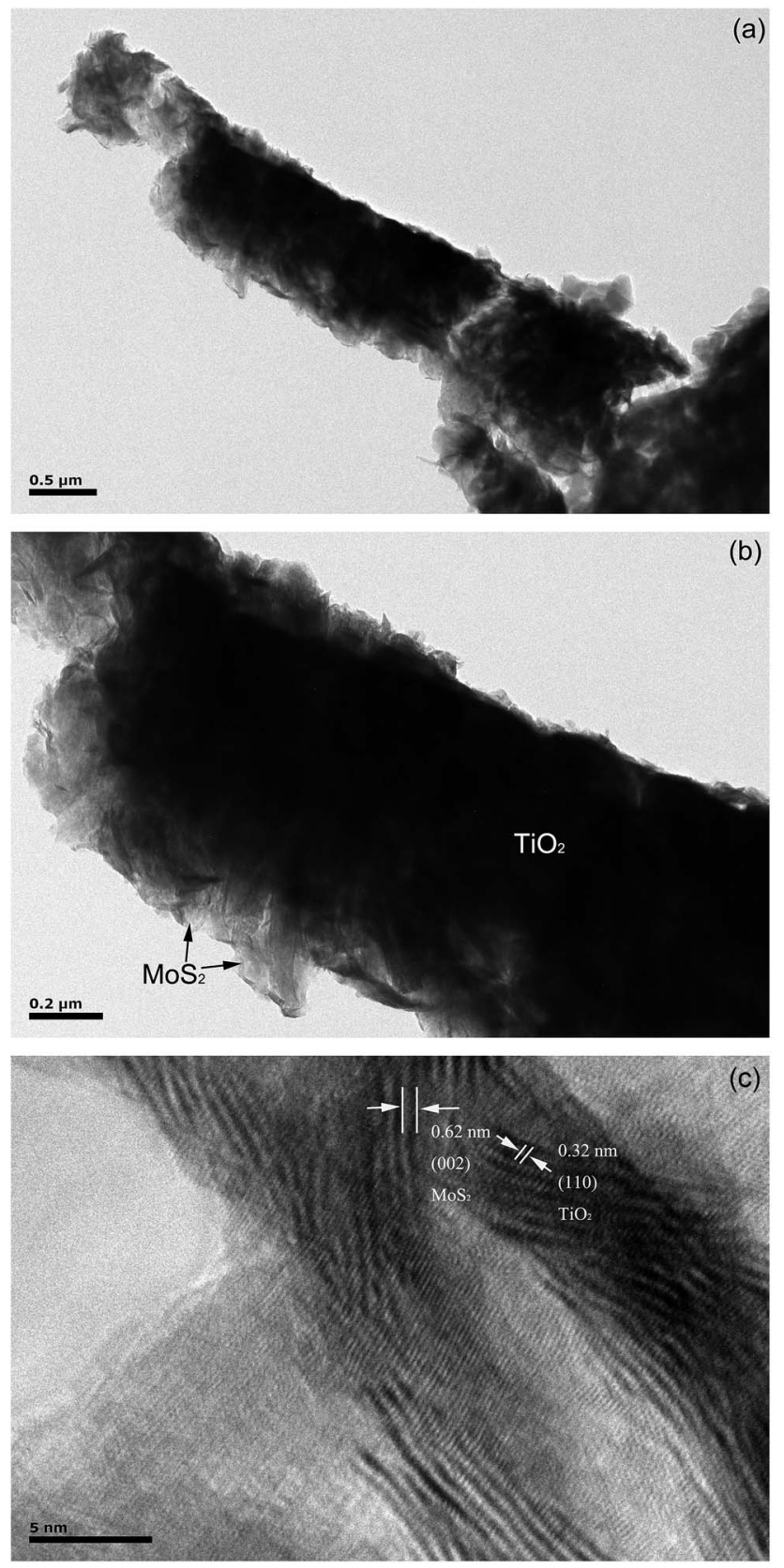

Fig. 3 (a and b) TEM images of $\mathrm{MoS}_{2}-220 / \mathrm{TiO}_{2}$ composites. (c) Highresolution TEM (HRTEM) images of pristine $\mathrm{TiO}_{2}$ NRAs.

respectively, of sulphide element in the divalent state. As shown in Fig. 4d, the C1s spectrum can be deconvoluted into three peaks, which correspond to $\mathrm{C}=\mathrm{O}(288.4 \mathrm{eV}), \mathrm{C}-\mathrm{O}(286.4 \mathrm{eV})$, and $\mathrm{C}-\mathrm{C}(284.8 \mathrm{eV})$, respectively. ${ }^{18}$ As shown in Fig. 4e, the spin-energy separation between Ti2 $\mathrm{p}_{1 / 2}(464.3 \mathrm{eV})$ and Ti2 $\mathrm{p}_{3 / 2}(458.5 \mathrm{eV})$ peaks is about $5.8 \mathrm{eV}$, which is assigned to the $\mathrm{Ti}^{4+}$ state in the pure $\mathrm{TiO}_{2}$ NRAs. ${ }^{19}$ The binding energies of Ti2 $\mathrm{p}_{1 / 2}(465.0 \mathrm{eV})$ and Ti2 $\mathrm{p}_{3 / 2}$ $(459.2 \mathrm{eV})$ for $\mathrm{MoS}_{2}-220 / \mathrm{TiO}_{2}$ shift to higher energies because of the existence of $\mathrm{Ti}^{3+}$ states by trapping electrons, ${ }^{\mathbf{1 6}}$ which exhibit higher activity and form the radicals covalently on the surface of $\mathrm{TiO}_{2}$. These trapped charge carriers can be transferred to the conduction or valence band by thermal excitation, which is beneficial to enhance the photocatalytic abilities. ${ }^{20}$ 

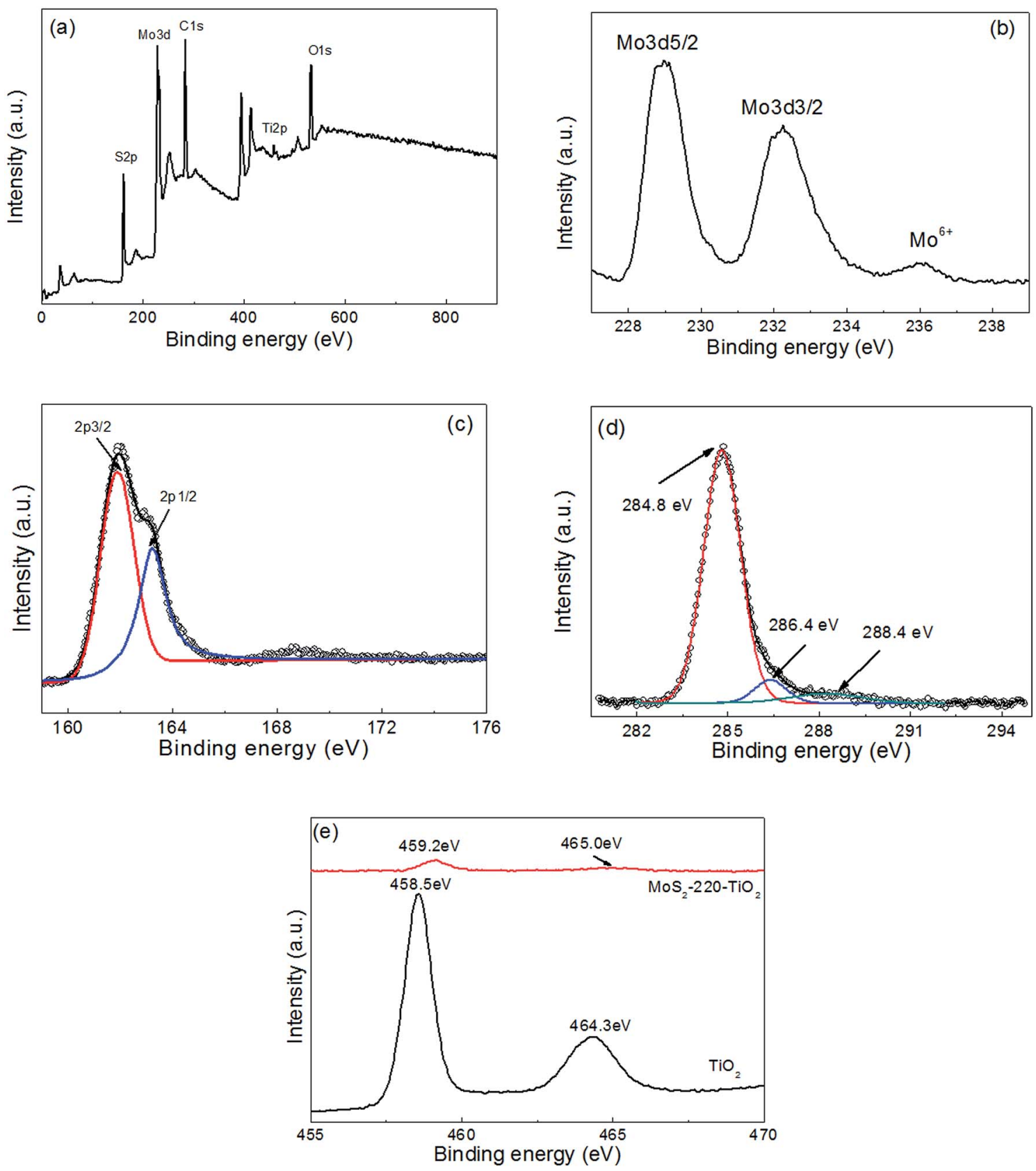

Fig. 4 XPS survey spectra of (a) $\mathrm{MoS}_{2}-220 / \mathrm{TiO}_{2}$, (b) $\mathrm{Mo}$ 3d, (c) S2p, (d) C1s, and (e) Ti2p.

Fig. 5 shows the Raman spectra of $\mathrm{TiO}_{2}$ NRAs, $\mathrm{MoS}_{2}-200 / \mathrm{TiO}_{2}$ and $\mathrm{MoS}_{2}-220 / \mathrm{TiO}_{2}$. It can be seen from the Raman curve of bare $\mathrm{TiO}_{2}$ NRAs that the two resonance peaks centered at 445 and $608 \mathrm{~cm}^{-1}$ can be attributed to the $\mathrm{B}_{1 \mathrm{~g}}$ and $\mathrm{E}_{\mathrm{g}}$ of $\mathrm{TiO}_{2}$ with rutile phase, respectively. ${ }^{21}$ There are three resonance peaks centered at 404, 445 and $608 \mathrm{~cm}^{-1}$, which can be observed from $\mathrm{MoS}_{2}-200 / \mathrm{TiO}_{2}$, which may be attributed to the out-of-plane $\mathrm{E}_{2 \mathrm{~g}}{ }^{1}$ of $\mathrm{MoS}_{2}$ and the $\mathrm{B}_{1 \mathrm{~g}}$ and $\mathrm{E}_{\mathrm{g}}$ of $\mathrm{TiO}_{2}$, respectively. ${ }^{22}$ These results indicate that a spot of $\mathrm{MoS}_{2}$ nanosheets deposited on the $\mathrm{TiO}_{2}$ NRAs. The Raman curve of $\mathrm{MoS}_{2}-220 / \mathrm{TiO}_{2}$ shows two strong resonance peaks centered at 375 and $404 \mathrm{~cm}^{-1}$, which may be ascribed to in-plane $\mathrm{A}_{1 \mathrm{~g}}$ and out-of-plane $\mathrm{E}_{2 \mathrm{~g}}{ }^{1}$ of $\mathrm{MoS}_{2}$, respectively. The other two weak resonance peaks centered at 445 and $608 \mathrm{~cm}^{-1}$ may be assigned to $\mathrm{B}_{1 \mathrm{~g}}$ and $\mathrm{E}_{\mathrm{g}}$ of $\mathrm{TiO}_{2}$, respectively, which weakened with the increase in $\mathrm{MoS}_{2}$ nanosheet content.

Fig. 6 shows the UV-vis absorption spectra of $\mathrm{TiO}_{2}$ NRAs, $\mathrm{MoS}_{2}-200 / \mathrm{TiO}_{2}$ and $\mathrm{MoS}_{2}-220 / \mathrm{TiO}_{2}$. It can be seen that the spectrum of $\mathrm{TiO}_{2}$ NRAs shows an abrupt absorption edge at about $400 \mathrm{~nm}$ and strong absorption in UV region. For $\mathrm{MoS}_{2}-$ 200/ $/ \mathrm{TiO}_{2}$ and $\mathrm{MoS}_{2}-220 / \mathrm{TiO}_{2}$, absorbance in the visible region has been enhanced due to the visible light absorbance arising from $\mathrm{MoS}_{2}$, which possesses the considerably narrowed band gap. These results indicated that the $\mathrm{TiO}_{2}$ NRAs were 


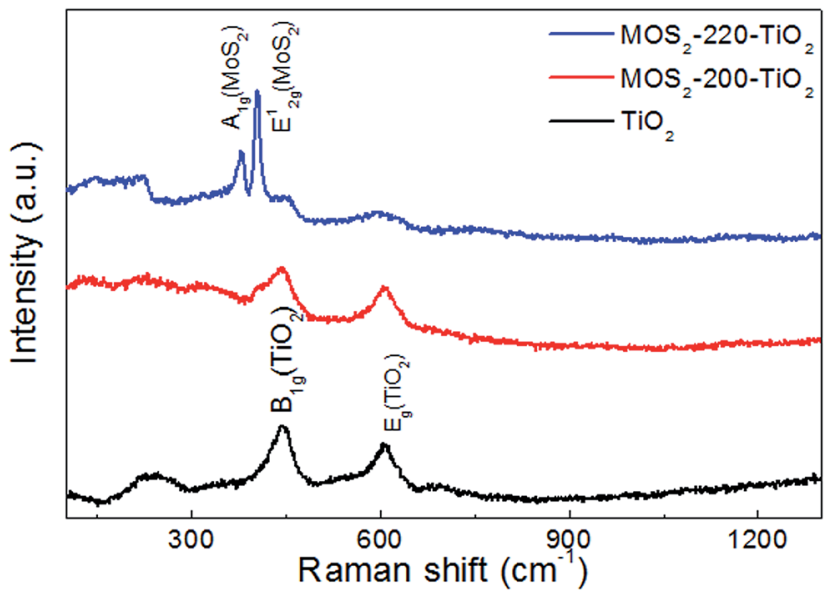

Fig. 5 Raman spectra of $\mathrm{TiO}_{2}$ NRAs, $\mathrm{MoS}_{2}-200 / \mathrm{TiO}_{2}$ and $\mathrm{MoS}_{2}-220 /$ $\mathrm{TiO}_{2}$.

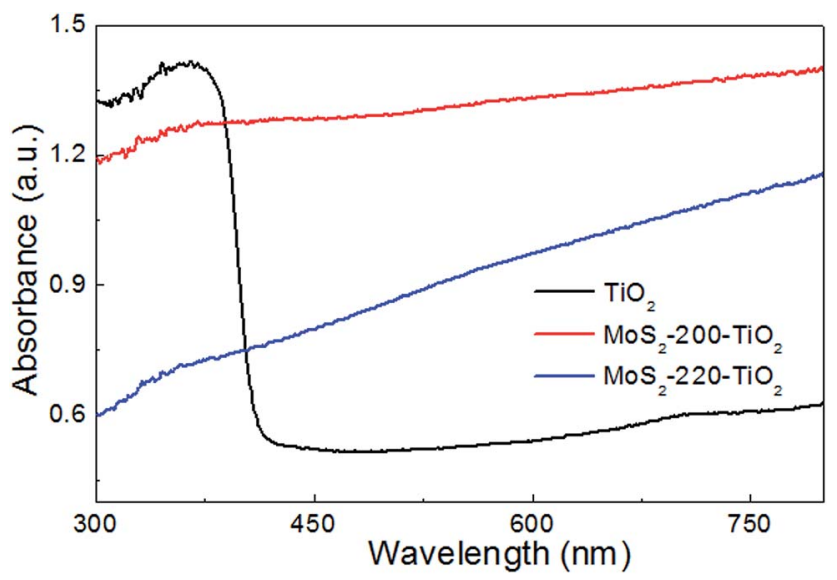

Fig. 6 UV-vis absorbance spectra of $\mathrm{TiO}_{2} \mathrm{NRAs}, \mathrm{MoS}_{2}-200 / \mathrm{TiO}_{2}$ and $\mathrm{MoS}_{2}-220 / \mathrm{TiO}_{2}$.

successfully modified by $\mathrm{MoS}_{2}$ nanosheets. The enhanced visible light absorbance of $\mathrm{MoS}_{2} / \mathrm{TiO}_{2}$ can improve the visible photocatalytic activity of the samples. ${ }^{21}$ It can also be seen that the UV absorption is greatly dependent on the amount of $\mathrm{MoS}_{2}$

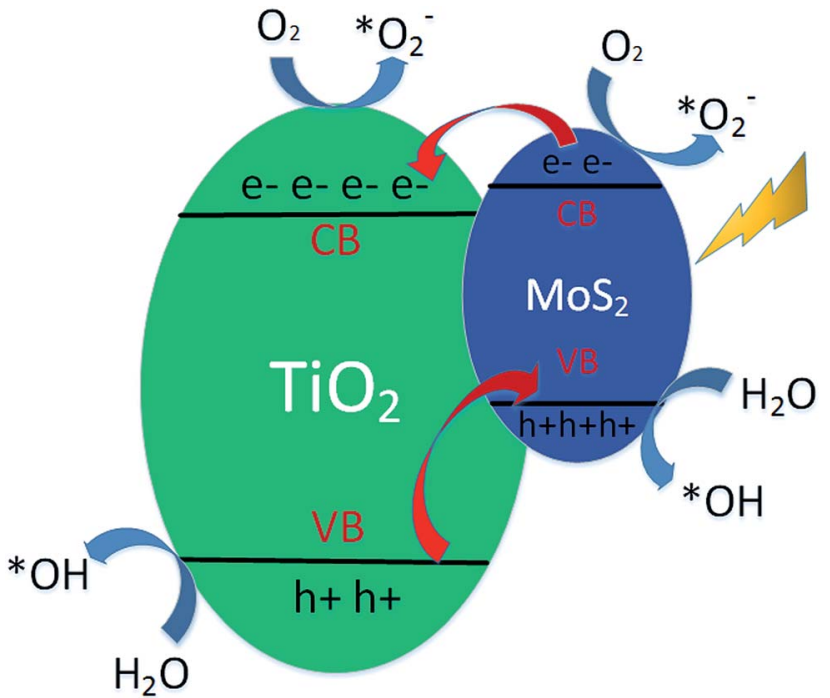

Fig. 8 Schematic of the energy band structure and separation principle of carriers in $\mathrm{MoS}_{2}-220 / \mathrm{TiO}_{2}$.

loaded onto $\mathrm{TiO}_{2}$. This may be attributed to the shielding effect of $\mathrm{MoS}_{2}$ on $\mathrm{TiO}_{2}$, which reduces the UV absorption of $\mathrm{TiO}_{2}{ }^{23}$

The photocatalytic performances of $\mathrm{TiO}_{2} \mathrm{NRAs}, \mathrm{MoS}_{2}, \mathrm{MoS}_{2}$ 200/ $/ \mathrm{TiO}_{2}$ and $\mathrm{MoS}_{2}-220 / \mathrm{TiO}_{2}$ were estimated by means of the photodegradation of MB under visible light. Fig. 7a shows the photodegradation rate of the samples. It is evident that the photodegradation rate of $\mathrm{MoS}_{2}-220 / \mathrm{TiO}_{2}$ is far greater than that of $\mathrm{TiO}_{2} \mathrm{NRAs}, \mathrm{MoS}_{2}$, and $\mathrm{MoS}_{2}-200 / \mathrm{TiO}_{2}$. The photodegradation rate of $\mathrm{TiO}_{2}$ NRAs, $\mathrm{MoS}_{2}, \mathrm{MoS}_{2}-200 / \mathrm{TiO}_{2}$ and $\mathrm{MoS}_{2}-220 / \mathrm{TiO}_{2}$ is about $44 \%, 53 \%, 57 \%$ and $86 \%$, respectively, after visible light irradiation for $180 \mathrm{~min}$.

The photodegradation of MB solution follows the pseudofirst-order reaction and its kinetics can be expressed as follows: ${ }^{17}$

$$
\ln \left(C_{0} / C\right)=k t
$$

where $C_{0}$ is the initial concentration of $\mathrm{MB}$ after adsorption equilibrium, $C$ is the concentration after $t$ min reaction, and $k$ is the rate constant. The $k$ values of $\mathrm{TiO}_{2} \mathrm{NRAs}, \mathrm{MoS}_{2}, \mathrm{MoS}_{2}-200 /$
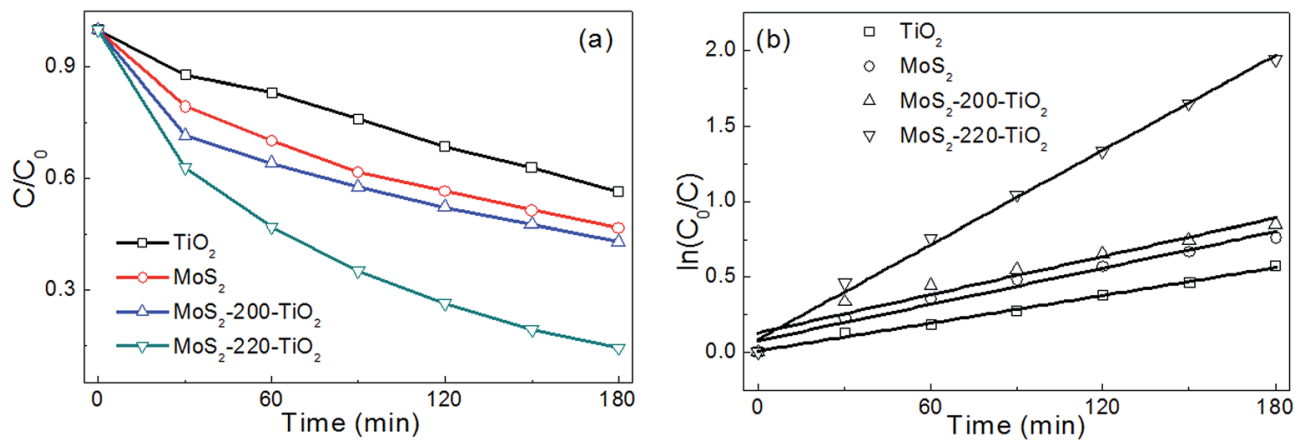

Fig. 7 (a) Normalized absorption of $\mathrm{MB}$ in the presence of $\mathrm{TiO}_{2} \mathrm{NRAs}, \mathrm{MoS}_{2}-200 / \mathrm{TiO}_{2}$ and $\mathrm{MoS}_{2}-220 / \mathrm{TiO}$ under visible light irradiation. (b) The plots of $\ln \left(C_{0} / C\right)$ versus $t$ of $\mathrm{TiO}_{2} \mathrm{NRAs}, \mathrm{MoS}_{2}-200 / \mathrm{TiO}_{2}$ and $\mathrm{MoS}_{2}-220 / \mathrm{TiO}_{2}$. 
$\mathrm{TiO}_{2}$ and $\mathrm{MoS}_{2}-220 / \mathrm{TiO}_{2}$ can be calculated from Fig. $7 \mathrm{~b}$ and are $0.0031,0.0040,0.0042$, and $0.0105 \mathrm{~min}^{-1}$, respectively. The $k$ value of $\mathrm{MoS}_{2}-220 / \mathrm{TiO}_{2}$ is almost 3.4 times greater than that of $\mathrm{TiO}_{2}$ NRAs. These results indicate that the photocatalytic performances of $\mathrm{TiO}_{2}$ NRAs can be considerably enhanced by the introduction of net-like $\mathrm{MoS}_{2}$.

For the as-deposited $\mathrm{TiO}_{2}$ NRAs, the photocatalytic degradation under visible light irradiation may be attributed to the existence of abundant defects, which will induce defect levels and narrow band-gaps and then improve the visible light absorption. ${ }^{24}$ The schematic of the energy band structure and separation principle of carriers in $\mathrm{MoS}_{2}-220 / \mathrm{TiO}_{2}$ is shown in Fig. 8. First, a small amount of electrons can be excited from the defect levels (or valence band) to the conduction band when $\mathrm{TiO}_{2}$ is illuminated by visible light. Second, it is well known that $\mathrm{MoS}_{2}$ is a narrow bandgap semiconductor with a band gap of about $1.8 \mathrm{eV}$. Upon visible light illumination, the electrons in the valence band (VB) of $\mathrm{MoS}_{2}$ can be excited to conduction band (CB), thus leaving holes in the VB. As the CB of $\mathrm{TiO}_{2}$ is lower than that of $\mathrm{MoS}_{2}$, the photogenerated electrons in the CB of $\mathrm{MoS}_{2}$ can be transferred to the CB of $\mathrm{TiO}_{2} \mathrm{NRAs}^{17} \mathrm{TiO}_{2}$ is considered to be an electron receiver, which is conducive to the separation of charge carriers. The electrons may be captured by oxygen $\left(\mathrm{O}_{2}\right)$ to form superoxide radical anions $\left({ }^{\circ} \mathrm{O}_{2}{ }^{-}\right)$, which can react with a simulated pollutant. In addition, the holes left in the VB of $\mathrm{MoS}_{2}$ can react with $\mathrm{H}_{2} \mathrm{O}$ to form hydroxyl radicals, which can react with the dye on the sample. ${ }^{25}$ Therefore, the electron and hole can be separated efficiently through the formation of a heterojunction between $\mathrm{MoS}_{2}$ and $\mathrm{TiO}_{2}$. Finally, the photocatalytic activities of $\mathrm{MoS}_{2} / \mathrm{TiO}_{2}$ could be enhanced by introducing $\mathrm{MoS}_{2}$ onto the $\mathrm{TiO}_{2}$ NRAs.

\section{Conclusions}

A novel $\mathrm{MoS}_{2}$ nanosheet decorating $\mathrm{TiO}_{2}$ NRA heterojunction composite with outstanding photocatalytic performance for the degradation of organic pollutants under visible light illumination was deposited by a hydrothermal method on the FTO substrate. SEM, XRD and Raman results confirmed that $\mathrm{MoS}_{2}$ nanosheets loaded on the surface of the $\mathrm{TiO}_{2}$ NRAs and filled the gap between $\mathrm{TiO}_{2}$ nanorods. Energy band structure of the $\mathrm{MoS}_{2}-220 / \mathrm{TiO}_{2}$ heterojunction composite could promote charge transfer and prevent the recombination of photogenerated electron-hole pairs. The $\mathrm{MoS}_{2}-220 / \mathrm{TiO}_{2}$ heterojunction composite exhibits the best photocatalytic activity, and the photodegradation rate and $k$ value are $86 \%$ and $0.0105 \mathrm{~min}^{-1}$, respectively.

\section{Conflicts of interest}

There are no conflicts to declare.

\section{Acknowledgements}

This study was supported by the National Natural Science Foundation of China (no. 51701001, 51102072, 51472003, and 51572002), Natural Science Foundation of Anhui Higher
Education Institution of China (no. KJ2015ZD32, KJ2017A924, and KJ2017A002), Doctor Scientific Research Fund of Anhui University (no. J01001927), Youth Core Teacher Fund of Anhui University (no. J01005111), Foundation of Co-operative Innovation Research Center for Weak Signal-Detecting Materials and Devices Integration Anhui University (no. Y01008411, and WRXH201703), and the Key Laboratory of Materials Physics, Institute of Solid State Physics, Chinese Academy of Sciences (no. 2016KLMP01).

\section{References}

1 J. Dong, X. Zhang, J. Huang, S. Gao, J. Mao, J. Cai, Z. Chen, S. Sathasivam, C. J. Carmalt and Y. Lai, Boosting heterojunction interaction in electrochemical construction of $\mathrm{MoS}_{2}$ quantum dots@TiO ${ }_{2}$ nanotube arrays for highly effective photoelectrochemical performance and electrocatalytic hydrogen evolution, Electrochem. Commun., 2018, 93, 152-157.

2 M. D. Patel, J. Zhang, J. Park, N. Choudhary, J. M. Tour and W. Choi, Directly deposited porous two-dimensional $\mathrm{MoS}_{2}$ films as electrocatalysts for hydrogen evolution reactions, Mater. Lett., 2018, 225, 65-68.

3 L. Yang, C. Xu, F. Wan, H. He, H. Gu and J. Xiong, Synthesis of $\mathrm{RGO} / \mathrm{BiOI} / \mathrm{ZnO}$ composites with efficient photocatalytic reduction of aqueous $\mathrm{Cr}(\mathrm{VI})$ under visible-light irradiation, Mater. Res. Bull., 2019, 112, 154-158.

4 C. Zhao, Y. Zhang, L. Chen, C. Yan, P. Zhang, M. A. Jia and X. Lu, Self-Assembly-Assisted Facile Synthesis of $\mathrm{MoS}_{2^{-}}$ Based Hybrid Tubular Nanostructures for Efficient Bifunctional Electrocatalysis, ACS Appl. Mater. Interfaces, 2018, 10, 23731.

$5 \mathrm{X}$. Lei, K. Yu, H. Li and Z. Zhu, A functional design and synthesization for electrocatalytic hydrogen evolution material on $\mathrm{MoS}_{2} / \mathrm{Co}_{3} \mathrm{~S}_{4}$ hybrid hollow nanostructure, Electrochim. Acta, 2018, 269, 262-273.

$6 \mathrm{~L}$. $\mathrm{Xu}$ and S. Wang, A novel hierarchical $\mathrm{MoS}_{2}-\mathrm{ZnO}-\mathrm{Ni}$ electrocatalyst prepared by electrodeposition coupling with dealloying for hydrogen evolution reaction, J. Electroanal. Chem., 2018, 808, 173-179.

7 W. Zhang, Z. Xie, X. Wu, M. Sun, X. Deng, C. Liu, Z. Liu and Q. Huang, Acid-engineered defective $\mathrm{MoS}_{2}$ as an efficient electrocatalyst for hydrogen evolution reaction, Mater. Lett., 2018, 230, 232-235.

8 Q. Xiong, X. Zhang, H. Wang, G. Liu, G. Wang, H. Zhang and H. Zhao, One-step synthesis of cobalt-doped $\mathrm{MoS}_{2}$ nanosheets as bifunctional electrocatalysts for overall water splitting under both acidic and alkaline conditions, Chem. Commun., 2018, 54, 3859-3862.

9 Z. Chen, D. Cummins, B. N. Reinecke, E. Clark, M. K. Sunkara and T. F. Jaramillo, Core-shell $\mathrm{MoO}_{3}-\mathrm{MoS}_{2}$ Nanowires for Hydrogen Evolution: A Functional Design for Electrocatalytic Materials, Nano Lett., 2011, 11, 41684175.

10 J. Xie, H. Zhang, S. Li, R. Wang, X. Sun, M. Zhou, J. Zhou, X. W. Lou and Y. Xie, Defect-rich $\mathrm{MoS}_{2}$ ultrathin nanosheets with additional active edge sites for enhanced 
electrocatalytic hydrogen evolution, Adv. Mater., 2013, 25, 5807-5813.

11 L. Liu, C. Luo, J. Xiong, Z. Yang, Y. Zhang, Y. Cai and H. Gu, Reduced graphene oxide (rGO) decorated $\mathrm{TiO}_{2}$ microspheres for visible-light photocatalytic reduction of $\mathrm{Cr}(\mathrm{VI}), \mathrm{J}$. Alloys Compd., 2017, 690, 771-776.

12 J. Kibsgaard, Z. Chen, B. N. Reinecke and T. F. Jaramillo, Engineering the surface structure of $\mathrm{MoS}_{2}$ to preferentially expose active edge sites for electrocatalysis, Nat. Mater., 2012, 11, 963-969.

$13 \mathrm{~J}$. Yang and H. Shin, Recent advances in layered transition metal dichalcogenides for hydrogen evolution reaction, $J$. Mater. Chem. A, 2014, 2, 5979-5985.

14 R. Chianelli, M. Siadati, M. P. L. Rosa, G. Berhault, J. Wilcoxon, R. Bearden $\mathrm{Jr}$ and B. Abrams, Catalytic Properties of Single Layers of Transition Metal Sulfide Catalytic Materials, Catal. Rev., 2006, 48, 1-41.

15 L. Zheng, S. Han, H. Liu, P. Yu and X. Fang, Hierarchical $\mathrm{MoS}_{2}$ Nanosheet@TiO 2 Nanotube Array Composites with Enhanced Photocatalytic and Photocurrent Performances, Small, 2016, 12, 1527-1536.

16 D. Qi, S. Li, Y. Chen and J. Huang, A hierarchical carbon@TiO $@ \mathrm{MoS}_{2}$ nanofibrous composite derived from cellulose substance as an anodic material for lithium-ion batteries, J. Alloys Compd., 2017, 728, 506-517.

17 C. Wang, W. Wan, Y. Huang, J. Chen, H. H. Zhou and X. X. Zhang, Hierarchical $\mathrm{MoS}_{2}$ nanosheet/active carbon fiber cloth as a binder-free and free-standing anode for lithium-ion batteries, Nanoscale, 2014, 6, 5351-5358.

18 S.-K. Park, J. Lee, S. Bong, B. Jang, K.-d. Seong and Y. Piao, Scalable Synthesis of Few-Layer $\mathrm{MoS}_{2}$ Incorporated into Hierarchical Porous Carbon Nanosheets for High-
Performance Li- and Na-Ion Battery Anodes, ACS Appl. Mater. Interfaces, 2016, 8, 19456-19465.

19 C. Ma, X. Wang, H. Luo and D. Zhang, Synthesis of Ag/TiO core-shell nanowires with enhanced stability of photocatalytic activity, J. Mater. Sci.: Mater. Electron., 2017, 28, 10715-10719.

20 P. Roy, S. Berger and P. Schmuki, $\mathrm{TiO}_{2}$ Nanotubes: Synthesis and Applications, Angew. Chem., Int. Ed., 2011, 50, 29042939.

21 F. Zhao, Y. Rong, J. Wan, Z. Hu, Z. Peng and B. Wang, $\mathrm{MoS}_{2}$ quantum dots@TiO ${ }_{2}$ nanotube composites with enhanced photoexcited charge separation and high-efficiency visiblelight driven photocatalysis, Nanotechnology, 2018, 29, 105403.

22 W. Jian, X. Cheng, Y. Huang, Y. You, R. Zhou, T. Sun and J. Xu, Arrays of $\mathrm{ZnO} / \mathrm{MoS}_{2}$ nanocables and $\mathrm{MoS}_{2}$ nanotubes with phase engineering for bifunctional photoelectrochemical and electrochemical water splitting, Chem. Eng. J., 2017, 328, 474-483.

23 J. Low, J. Yu, M. Jaroniec, S. Wageh and A. A. Al-Ghamdi, Heterojunction Photocatalysts, Adv. Mater., 2017, 29, 1601694.

24 Z. Wu, S. Cao, C. Zhang and L. Piao, Effects of bulk and surface defects on the photocatalytic performance of sizecontrolled $\mathrm{TiO}_{2}$ nanoparticles, Nanotechnology, 2017, 28, 275706.

25 J. Lv, R. Miao, M. Zhang, G. He, M. Zhao, B. Yu, W. Wang, B. Li and Z. Sun, Few-layers $\mathrm{MoS}_{2}$ sensitized $\mathrm{Ag}-\mathrm{TiO}_{2}$ nanocomposite thin film for enhancing photocatalytic activity, J. Mater. Sci.: Mater. Electron., 2018, 29, 1628216288. 